\title{
Behavioral integrity as a critical ingredient for transformational leadership
}

Tony L. Simons

School of Hotel Administration, Cornell University, USA

Keywords Fashion, Individual behaviour, Leadership, Trust

Abstract: Behavioral integrity is the perceived fit between espoused and enacted values. We propose that the maintenance of behavioral integrity is a highly problematic and consequential element of the successful management of change. Support for this view is drawn from the literatures on management fads, transformational leadership, trust and source credibility. Practical implications are developed. 
The insight that drives this paper is a growing personal suspicion that most managers in America today pretend to be nicer than they really are. Modern managers talk a lot about caring for employees, about customer service, and about participativeness and creativity. However, implementations of these and other admirable programs are often superficial, and can generate more jargon and lofty promises than actual change in routines and underlying values (Kouzes and Posner, 1993). Terry (1993, p. 113) and other leadership scholars have noted an increasing pattern of divergence between managers' words and deeds. We propose that this divergence is largely driven by managers' understandable responses to managerial fads and to organizational change efforts. Abrahamson (1996) documents widespread patterns in the Fortune 500 of brief adoption of popular managerial techniques and philosophies, followed by their abandonment a few years later. Abrahamson argues that this cycle of adoption and abandonment has continually accelerated in the years since the early 1980s. Change projects by their nature risk generating perceptions of managerial word-action misfit through managerial ambivalence, confusion, and other mechanisms to be discussed in this paper. This risk is increased when change projects follow each other in a succession of abortive managerial fashion implementations. This paper proposes that the divergence between words and deeds has profound costs as it renders managers untrustworthy and undermines their credibility and their ability to use their words to influence the actions of their subordinates. In their efforts to implement and to cope with change at the social and the organizational levels, many managers are sacrificing their most powerful resources: their personal credibility, and the trust and commitment of their subordinates.

The trust of subordinates in their managers is widely recognized as critically important. Bass (1985) described subordinates' trust as a consequence of transformational leadership, but trust may also be seen as an integral component of charismatic leadership (Bass, 1990; Bycio et al., 1995), or as an antecedent to charismatic leadership (Carlson and Perrewe, 1995; Kouzes and Posner, 1992; Yukl, 1989). Bartlett and Ghoshal (1995, p. 18) argue that trust is essential for managing change because trust is necessary for risk-taking, and personal risk-taking is integral to organizational change. Transformational leadership is often identified by the effect that it has on followers' attitudes, values, assumptions and commitments (Yukl, 1989). If subordinates are to willingly change their attitudes, values, assumptions and commitments to bring them more closely in line with those of the organization, they must have deep trust in the integrity and credibility of their leader (Carlson and Perrewe, 1995; Kouzes and Posner, 1992; Kouzes and Posner, 1993).

This paper will first briefly define the construct of behavioral integrity. Then, we will discuss relevant research and theory on transformational leadership, trust and credibility to lead the reader 
to appreciate behavioral integrity as a highly consequential and woefully under-studied phenomenon that is pivotal to the successful navigation of organizational change. We will then discuss social and organizational antecedents of the divergence between managers' words and deeds to lead the reader to appreciate the issue of behavioral integrity as a widespread problem. Finally, we will develop some implications for research and practice.

\section{Definition of the construct}

Behavioral integrity (BI) is the perceived degree of congruence between the values expressed by words and those expressed through action. It is the perceived level of match or mismatch between the espoused and the enacted.

BI is the extent to which a perceiver believes that the organization and/or the managers in it represent themselves and their motivating values accurately in their communications with employees. BI involves the extent to which a manager walks her talk'', and, conversely, the extent to which she talks her walk''. The Random House College Dictionary (1975) defines integrity as adherence to moral and ethical principles''. BI, however, does not consider the morality of principles, but rather focusses on the extent to which stated principles match actions. As discussed elsewhere, BI is fundamentally a subjectively perceived phenomenon, and is thus susceptible to perceptual bias (Simons, 1997). Behavioral integrity entails an internal attribution for word- action match or mismatch, and may be ascribed to an individual manager ("John means what he says.") or to a larger entity ("The management of this company blows a lot of smoke at the annual meeting.").

\section{Related literature}

\section{Transformational leadership}

A consideration of transformational leadership indicates the importance of subordinates' belief in their managers' words, and their consequent trust, if that manager is to play the role of a transformational leader. Yukl (1989) describes transformational leadership as a process whereby the leader enhances organization members' affective commitment by getting them to profoundly alter their attitudes and assumptions about work. Clearly, the harnessing of this ability to exert profound influence would be a boon for the successful management of change.

Bass (1985) describes transformational leadership as comprising three factors: 
1. charismatic leadership, based on admiration and respect;

2. individualized consideration for the subordinates' needs; and

3. intellectual stimulation or encouragement for subordinates to view challenges in new ways.

of these three components, the charismatic leadership dimension has consistently represented the strongest single predictor of leadership outcomes, including subordinate extra effort, commitment to the organization, satisfaction with the leader, and subordinates' assessment of leadership skills (Bass, 1990; Bycio et al., 1995). Charismatic leadership is a key element of transformational leadership, as Bass (1985) notes that charismatic leadership forms a necessary but not sufficient condition for transformational leadership.

It is alarming in the face of this importance that charismatic leadership measurement scales have often failed to hold together as factors (Bycio et al., 1995; Hinkin and Tracey, 1999). This difficulty of measurement could represent a call for deeper exploration of the processes and preconditions for charismatic leadership. A full refinement of the concept of charismatic leadership is beyond the scope of the present work. However, the literature strongly suggests that trust and credibility represent necessary antecedents for charismatic influence. Charismatic leadership is often described using words like trust (Bass, 1990; Yukl, 1989) and credibility (Bass, 1990). These elements are sometimes considered as outcomes of charismatic leadership, but they might well be antecedents (Carlson and Perrewe, 1995; Kouzes and Posner, 1992; Yukl, 1989) or integral components of the process (Bass, 1990; Bycio et al., 1995).

To better understand the mechanisms of charismatic leadership, it is reasonable to inquire about the conditions that give rise to trust and credibility. Carlson and Perrewe (1995) propose that consistent delivery on promises and commitments is necessary for transformational leadership. More broadly, several sources have specified the need for modeling of key values as a component of charismatic leadership (e.g. Bass, 1990). Yukl (1989) describes managerial actions, attention distribution, and decision patterns as ways in which the charismatic leader communicates his vision. Kouzes and Posner (1992, p. 483) note that we are more willing to entrust a leader with our careers, our security, and sometimes even our lives, if that person practices what he or she preaches''. Delivering on promises and modeling values are critical elements of behavioral integrity.

The kind of profound influence that a follower grants to a charismatic leader requires trust. That kind of trust requires the follower to perceive the leader as honest or as possessing integrity (Bass, 1990; Carlson and Perrewe, 1995; Korsgaard et al., 1995; Kouzes and Posner, 1992), and that perception is best built and maintained 
through a pattern of actions that are consistent with espoused values (Kouzes and Posner, 1992; 1993; Kramer, 1996), or, more concisely, through the maintenance of behavioral integrity. Transformational leadership often relies on charismatic leadership, and charismatic leadership requires trust and credibility among employees. This paper will argue that the development of trust and credibility among employees requires behavioral integrity.

\section{Trust}

While the construct of trust has received considerable recent attention, scholars continue to rely on diverse definitions of the construct. Definitions of trust have focused on intent, on risk and vulnerability, on ethical justifiability, and/or on value congruence. Within most of these diverse frameworks, the belief that a person's words accurately predict future actions forms a necessary, though perhaps not sufficient, condition for the development of trust.

Several recent scholars have focused their definitions of trust on the notion that the trustor believes that the trusted party will behave in a way that is beneficial to the trustor. Hosmer (1995, $p$. 393) synthesizes definitions from much previous work, and proposes that trust is the reliance. . . on a voluntarily accepted duty on the part of another. . . to recognize and protect the rights and interests of all others engaged in a joint endeavor or economic exchange.'' Robinson (1996) similarly defines trust as one's expectations or beliefs about the likelihood that another's future actions will be beneficial, or at least not detrimental, to one's interests''. By these definitions, trust is a person's sense that another will protect and maximize the trustor's interests - the extent to which the trusted person is expected to sacrifice her own interests in doing so is not specified. Benevolence is integral to these definitions of trust.

Other scholars have focused on the element of vulnerability or risk in their definitions of trust. Mayer et al. (1995, p. 712) define trust as the willingness of a party to be vulnerable to the actions of another party based on the expectation that the other will perform a particular action important to the trustor, irrespective of the ability to monitor or control the other party''. These approaches to trust describe a largely rational approach that involves the assessment of the likelihood of non-exploitation by another in an environment where monitoring is difficult.

Several conceptualizations of trust have been explicitly multidimensional. Mishra (1996, p.265) draws on the concept of vulnerability, but borrows from several other sources to define trust as one party's willingness to be vulnerable to another party based on 
the belief that the other party is (a) competent, (b) open, (c) concerned, and (d) reliable''. Mayer et al. (1995, p. 717) review substantial literature on factors that lead to trust, and conclude that the three factors of ability, benevolence and integrity appear frequently and seem to explain much of trustworthiness.

Rotter's (1967, p. 650) definition of trust comes closest to behavioral integrity. Rotter defines interpersonal trust as an expectancy held by an individual or a group that the word, promise, verbal, or written statement of another individual or group can be relied on''. This perception of reliability, while it is more limited than other definitions of trust, is likely to be a closely- related consequence of the perception of congruence between words and actions.

Despite some discrepancies regarding the specific definition of trust, there is widespread support for the notion that this elusive construct has important consequences. Tyler and Degoey (1996) propose that employee trust in management enhances subordinates' compliance with organizational rules and laws, increases the zone of indifference, and facilitates the implementation of organizational change. Robinson (1996) found that employees' trust in their employers directly influenced those employees' contributions to their organizations in terms of performance, intent to remain with the organization, and civic virtue behavior.

Diverse approaches to trust have, with some consistency, described the belief in the truthfulness of another's verbal representations as either a central component of trust, or as a critical antecedent of it. Korsgaard et al. (1995, p. 62) note that a person's belief in the honesty and sincerity of a leader are pivotal components of that person's trust in that leader. Mayer et al. (1995) describe integrity as one of three factors that comprise perceived trustworthiness. Mishra (1996, p. 266) notes that a key aspect of trust is the perception of openness and honesty on the part of the other. Cummings and Bromiley's (1996) definition of trust includes a perception of honest self-representation. These scholars and others have considered constructs close to BI as being a constituent part of trust.

others have described perceptions akin to behavioral integrity as antecedents of trust. McGregor preceded most research on organization behavior in his observation that inconsistencies between words and deeds decreases trust (1967, p. 164). Mishra (1996, p. 273) notes how trust entails beliefs about another party's openness, and considers further how lies and distortions decrease trust, while undistorted communication reinforces trust. Butler (1991) explored the attribution of integrity among other antecedents of trust. Butler factor analyzed conditions of trust for 380 students, and found that the attribution of integrity was the closest condition to the construct of overall 
trust in a specific person'' (p. 652). In fact, the two elements were so closely aligned in respondents' perceptions that they loaded on a single factor - which suggests that the antecedent is so strong as to be nearly indistinguishable from the consequence.

Lewicki and Bunker (1996) offer a sequential perspective for the role of behavioral integrity in the establishment of trust. In their conceptual framework, deterrence-based trust (sometimes called, calculus-based trust') is based on constancy of behavior - that people will do what they say they are going to do'' (Lewicki and Bunker, 1996, p. 118). Further, Lewicki and Bunker propose a sequential development in work relationships from calculus-based trust to more intimate, empathic, and exclusive forms of trust. These authors argue that a failure at any of these types of trust precludes progress to the next level of trust. By this reasoning, a failure to ''do what you say you are going to do'' might completely arrest the development of trust. McAllister (1995) makes a nearly identical argument with slightly different terminology. Within both of these different frameworks, a person who is perceived as not doing what she says might have substantial difficulties in establishing any trust at all - and, by implication, that the perception of behavioral integrity may be a necessary condition for the establishment of trust.

One of the ways in which word-action mismatches undermine trust is through norms of reciprocity. Managers' misrepresentation of their priorities may be seen as behavior that denotes mistrust. When employees perceive that their managers do not trust them, they tend in turn to mistrust those managers (Creed and Miles, 1996). Gambetta (1988, p. 216) adds that this reciprocity will ultimately influence employees' cooperation behavior as cooperation requires the belief that one is trusted by others. One of the reasons why managers misrepresent is because they do not trust their subordinates with the truth - and this apparent mistrust not only causes subordinates to reciprocate with less trust, but can also cause the subordinates to in turn behave in a less trustworthy manner.

Though researchers have diverged in their struggles to define trust, they have spoken with a consistent voice in proposing that the perception of fit between words and actions, and the sense that a person's words can be relied on, are either a central component of trust, or are a critical antecedent to trust. For the current work, I use the latter conceptualization, as trust appears to be more multidimensional than behavioral integrity, and to involve affective components and beliefs about competence, benevolence and value congruity.

Credibility 
Credibility issues are central to the thrust of the current work. Kouzes and Posner (1993) centered their prescriptive research on the notion of leader credibility. They asked people to define the behaviors and evidence that they use in assessing a leader's credibility. ''The most frequent response was 'they do what they say they will do'. Similarly, people would say, 'they practice what they preach'. 'They walk the talk'. 'Their actions are consistent with their words''' (p. 47). Credibility in ongoing managerial relationships appears to be strongly influenced by perceived patterns of word-action congruence, or behavioral integrity.

Kouzes and Posner (1993) propose that managers earn and strengthen their credibility when they simply do what they say they will do (p. 47, p. 248). Further, they note that this effort at consistency is often made difficult by environmental changes and by the need to experiment with new managerial approaches. Despite the difficulties of achieving credibility, Kouzes and Posner argue that credibility is a necessary condition for the development of employee loyalty and commitment. If transformational leadership can be assessed by the effect it has on followers (Yukl, 1989), Kouzes and Posner's argument suggests that behavioral integrity might be a pivotal component of transformational leadership.

A consequence of managers' low credibility is that the managers' words lose effectiveness as an instrument of change. Leaders' exhortations of a new mission or a new focus are processed by employees as simply a new dogma or corporate presentation, and are not translated into action. An executive quoted in Mishra (1996, p. 267) summarizes this effect well:

If they don't believe what I'm telling them, if they think it's all a bunch of bull, don't expect them to go out there and work a little harder or work a little different. They're not going to be as receptive to change unless they understand and trust that the things we're talking about are in fact true.

Words are one of a manager's most potent tools for guiding subordinates at all levels of the company. When credibility is sacrificed, the manager damages that tool, and is forced into additional actions to show when he or she really means'' what he or she says.

Within the frameworks of both managerial and source credibility, the perception of behavioral integrity has so direct an impact on credibility as to risk tautology. A distinction can be made, however, in that behavioral integrity is backward-looking and focusses on the past fit between words and actions. Credibility, on the other hand, is forward-looking, and focusses on the weight that can be placed on future statements. 


\section{other leadership theories}

Theories of leadership and change outside of the transformational leadership stream have also recognized the perceived fit between managerial espousal and action, as a central success factor. Collins and Porras (1991; 1995; 1996) explicitly downplay the importance of personal charisma in their formulation of vision and visionary companies. However, their ideas closely parallel behavioral integrity theory on several issues, and serve to further illuminate the present discussion. Collins and Porras (1996, p. 71) offer that the authenticity, the discipline, and the consistency with which the ideology is lived - not the content of the ideology - differentiate visionary companies from the rest of the pack''. They add, more succinctly, that building a visionary company is 1 per cent vision and 99 per cent alignment'' ( $p .77$ ).

Collins and Porras (1991, p. 36) describe one of the more serious pitfalls that managers encounter in their efforts to clarify their core values and beliefs. The key challenge for this task must be to define what values and beliefs the management actually hold in their guts, and not what values and beliefs the management believes that they should hold. When managers present their aspired-to values as though they were actual values, rhetorical statements rather than actual value-driven behavior will result, and people will respond with justifiable cynicism''. This tension between actual and aspired-to values, and managers' confusion between the two, forms a critical challenge for the maintenance of $\mathrm{BI}$.

Hamel and Prahalad $(1989 ; 1994)$ describe strategic intent as an active process that entails setting and communicating a target, and using that objective to guide resource allocations. This process provides a sense of purpose that motivates employees, activates and focusses their emotional and creative energies, and presents a unifying sense of purpose that makes individual efforts cumulative'' (Hamel and Prahalad, 1994, p. 130). Hamel and Prahalad note that this intent, in order to be effective in guiding and motivating employees, must be stable over time $(1989,1994)$ and that it must be consistently reinforced across organizational levels (1989). Behavioral integrity, while not directly discussed, is likely to be one of the key mediating mechanisms by which this prescription operates.

Hamel and Prahalad's discussions serve to highlight additional threats to behavioral integrity. They point out that middle managers are often forced to compensate for senior management's failure to prioritize various improvement goals. In these cases, managers often convey mixed messages and conflicting signals that inhibit momentum for any of those goals (Hamel and Prahalad, 1994, p. 163). A lack of top-down operating priorities can cause managers to send inconsistent messages to their subordinates as they attempt to guess their 
superiors' unstated desires. Employees' perception of this inconsistency, in turn, can undermine that manager's BI. A rapid succession of operational improvement priorities can also undermine BI. Hamel and Prahalad (1989, p. 67) note that any corporate operational challenge should be digested'' before another is launched, and this digestion takes time. Competing initiatives, they argue, should be avoided because the presence of multiple, rapidly shifting priorities can incite managers to shelter their employees from the apparent caprice of the senior officers. When managers adopt such a wait and see'' attitude, the credibility of corporate challenges is destroyed. The suggestion that rapid shifts in priorities can erode the credibility of change efforts seems to describe an element of behavioral integrity. The argument highlights the complex interplay of managers serving as interpreters and intermediaries of their superiors' change proposals. The nature of this complexity, and the different potential loci of BI breach involved, warrants further exploration.

The consideration of the impact of managers' word-action congruence has not been limited to scholars of the transformational leadership schools. A brief review of other literature on leadership and change suggests that the issue can be readily detected as a central tenet of many leadership theories, and that the synthesis of these different perspectives on behavioral integrity can readily serve to deepen our comprehension of this critical issue. The preceding discussion explores only a few exemplars. Further examinations of this literature are likely to lead to further insights about the nature and function of behavioral integrity.

\section{Antecedents to BI breaches}

There are several sources for the emergence of BI as a problem in organizations. Some explanations focus at the inter-organizational or societal level of analysis, others focus primarily within the organization and within the manager. Common themes to these sources of BI breaches are the notions of change and impression management. Following is a discussion of several of those antecedents and their managerial implications.

Managerial fads and fashions

One of the key sources of low managerial integrity is the phenomenon of managerial fads and fashions (Abrahamson, 1991) and the organizational and managerial responses to such fads. Ghoshal and Bartlett (1996) note that the average company, between 1990 and 1994, had committed itself to 11.8 of 25 currently popular management tools and techniques. Abrahamson (1996) describes research to the effect that fully one-third of all US organizations with more than 500 
employees reported adopting quality circles between 1980 and 1982, including 90 percent of the Fortune 500. A survey conducted in 1988, also reported by Abrahamson (1996), indicated that 80 percent of the Fortune 500 companies that adopted quality circles in the early 1980s had dropped them by 1987. It is clear that management practices have waxed and waned in popularity, and that the cycle time of program acceptance and rejection is at times quite rapid.

Abrahamson (1996) points out that constant change in shared beliefs about management progress is in part necessitated by the need of managers to appear to be at the forefront of management progress. The desire to appear to be a sophisticated manager was promoted in part by the tremendous increase in graduate management education, as MBA-trained managers sought to prove their worth by implementing and espousing the most current techniques, and as non-MBA-trained managers sought to resemble MBA-trained managers. The 1980s saw an explosion of consultants and of management books as companies sought to respond to new competitive threats by adopting new management technologies. Much of the change process as implemented by companies, though, focussed on superficial trappings (Kouzes and Posner, 1993, p. 22). It is a profound irony that managerial credibility has been undermined by precisely the same actions that managers have undertaken in their efforts to muster credibility (Zucker, 1986).

Change-oriented jargon is one key generator of BI violation. Shapiro (1995, p.49) proposes that changes in the jargon that is used to describe employees and managers does little to alter the wellestablished power dynamics in an organization, and that it has the primary effect of obscuring the reality from the less savvy actors. While modifications of language might have some impact on how organization members function, for this impact to last, it has to be supported by a coordinated change effort (Argyris, 1970). However, remnants of the language tend to remain in use even in the absence of such coordination, often long after support for the change effort has been withdrawn or redirected. When the language does not match the reality, behavioral integrity is eroded.

Shapiro (1995) and Argyris (1990) discuss the divergence between words and actions as a consequence of companies' dabbling in managerial fads. Shapiro describes the situation where espoused rules or priorities differ from real (enacted) rules: . . no matter how piously such official sentiments are repeated, in their actions the savvy players will always. . . follow the real rules for gaining rewards and avoiding punishments'' (p. 59). When the official policies and managerial philosophy statements of a company do not match the way things really get done on a day-to-day basis, smart organizational members learn quickly to discard the official rulebook and to play by the true rules of the game. The incongruity between the espoused and 
enacted rulebooks'' threatens the behavioral integrity of an organization's management.

A practical implication of managerial fads as a source for BI violation is that executives should let go of the search for a quick fix. Fundamental organizational change should be undertaken either systematically, with sustained effort and focus, or not at all. This phrasing is extreme, but managers should recognize in considering change implementation that dabbling and experimentation with different managerial approaches may have costs that outweigh the benefits. If experimentation with managerial approaches is considered to be necessary or appropriate for an organization, careful attention must be paid to maintaining employee perceptions of continuity and BI through such experimentation.

\section{Organizational change}

BI incongruities can emerge from multiple abortive change efforts, as detailed above, but they are likely to also emerge during the process of sustained change efforts, as different elements of the organization change at different paces. Robinson (1996, p. 574) notes that constant contract change means increased opportunities for employees and employers to misunderstand the agreement and to perceive a contract breach even when an actual breach did not occur''. Since the assessment of behavioral integrity is a subjective process, misunderstandings that emerge from policies and procedures in flux can reduce perceptions of behavioral integrity. Further, different elements within the organization's structure are likely to adopt new approaches at different paces, which in turn leads to different messages'' coming from different parts of the organization.

Some inconsistency is inevitable during any fundamental change process. The danger is that the perception of such inconsistency will undermine employees' assessment of the behavioral integrity (and thus the sincerity) of the manager or team that champions the change. Change managers would do well to anticipate and acknowledge to their employees that such inconsistencies will arise. They could further enlist their employees' assistance in ferreting out policies, procedures and behavior that contradict espoused changes. A suggestion box where employees can point out these inconsistencies can transform evidence of hypocrisy into opportunities to assist in change efforts. Where the inconsistencies are not readily correctable, frank discussion would assist in shifting the attribution for the inconsistency from hypocrisy on the part of managers toward external circumstances, and this to reduce the impact on BI. 


\section{Individual responses to change}

Problems in behavioral integrity can also emerge from managers' individual resistance to change efforts. Resistant managers often attempt to put up an appearance of supporting the change project while actual behavior remains unchanged. Shapiro (1995, p. 91) describes the ambivalent or insecure manager's response to empowerment programs as sabotage'', and admonishes such managers to refrain from using empowerment jargon, as this use will only raise false expectations on the part of employees. When managers find themselves torn between the demands of their superiors and their personal preferences, or between the management practices they believe to be desirable and those with which they feel most comfortable, they often send different messages through their words and their actions.

A practical implication of this argument is that time taken to individually assess and coach all the managers affected by a change process may be a prudent investment. Individual managers' resistance to change can emerge from a variety of sources - some are addressable, and some are not. The key point here is that this resistance needs to be individually measured and, if possible, addressed at all management levels, not just the most senior levels. The goal is to anticipate and correct managerial behavior that undermines the change process, whether or not that behavior is consciously intended.

\section{Individual self-knowledge}

Managerial self-knowledge affects managers' BI. A manager can only represent her priorities and preferences accurately if she knows what they truly are. Poor self-understanding can easily lead to unintended inaccuracies in self-portrayal, unanticipated changes, and inconsistent behavior. Kouzes and Posner (1993, p. 60) describe the vulnerability of this phenomenon:

If leaders are not clear about what they believe in, they are much more likely to change their positions with every fad or opinion poll. Without core beliefs and with only shifting positions, would-be leaders will be judged as inconsistent and will be derided for being political'' in their behavior. The first step on the credibility journey is thus clarification of values.

Thus, management education represents a two-edged sword: to the extent that it promotes efforts to implement the latest management fad, it threatens behavioral integrity. To the extent that it promotes introspection and clarification of one's own values, it enhances behavioral integrity.

The implication here is fairly straightforward; where management practices imply values - for example, innovation, service or 
egalitarianism - managers should understand clearly and explicitly how they personally feel about these implications. Activities that are aimed at the clarification of relevant personal values are likely to support organizational change processes. However, such activities need to be cognizant in their design of the strong impression management demands experienced by managers in such a workshop situation. A second approach could be the integration of survey feedback from subordinates about the values implied by their manager's actions. Managers might be surprised to see how they are perceived, and should be encouraged to consider whether their employees' perceptions of their actions might represent an accurate picture of their enacted values - and thus, perhaps, of their true'' values.

An accelerating loop: managerial dissociation and the split-brain syndrome

When a manager's own words and deeds are incongruent with each other for a sustained period of time, mechanisms that resemble internal impression management and the need to appear consistent (Fiske and Taylor, 1991) become active to divert managers' attention away from these inconsistencies or potential hypocrisies. Thus, the more a manager's actions are incongruent with her words, the less aware she becomes of these incongruities - and hence the more likely she is to enhance and perpetuate them.

Shapiro (1995) describes an array of responses to official slogans and mission statements that are unsupported by actual reward systems in the organization. Some employees will become increasingly frustrated as they attempt to bridge the large gap between the espoused and the actual. Others will become cynical and contemptuous of their leaders. The majority, however, will learn to compartmentalize or dissociate the speaking'' and the action' ' parts of their work. In many organizations the manager's path to success seems to lie in verbal endorsements of espoused values coupled with actual behavior that is in line with more widely accepted implicit norms and standards, and the two often do not match. Shapiro's observation suggests that many managers respond to this kind of environment by accepting it and by minimizing their awareness and examination of any incongruity between their words and their deeds. Argyris (1990, p. 62) similarly observes that managers in an environment where espoused values do not match with actions will talk the espoused while behaviorally following the enacted, and will defensively tend to resist self-examination.

Social cognition research offers a few models to explain this pattern of behavior. Swann and Read (1981) note that people have preferential recall for behaviors that are consistent with their selfimage. To the extent that few people like to think of themselves as 
speaking one way and acting another, they are unlikely to retrieve evidence that this is the case. Carver (1979) and Carver and Scheier (1981) argue that people often choose not to attend to instances of their own less-than-ideal behavior, especially when they feel powerless to correct the deficiency. Fiske and Taylor (1991) summarize extensive empirical support for this model of attentional processes.

The practical implication of this dissociation mechanism is that managers, even with the best of intentions, might be unreliable informants about their own levels of behavioral integrity. Vigilance toward the seduction of self-delusion might help a little in ameliorating the tendency. A more effective method would be routine surveys of employees to assess the extent to which they perceive their managers' words lining up with actions. Perceived gaps might signal a need for a manager to reconsider their espousals, to alter their behavior, or to better manager-employee attributions. As with all such

feedback, the confidentiality of the process and the way that feedback is delivered and used require careful attention.

\section{Summary}

Behavioral integrity has emerged as a highly problematic element in the current environment of near-continuous organizational change. It is difficult for managers to maintain congruence between words and deeds and to ensure that their subordinates perceive this congruence. Further, examination of the literatures on transformational leadership and trust offers a strong implication that the challenge of maintaining behavioral integrity is critical for the development of employee trust and commitment that are vital for successful change efforts. If that were not enough, the literature on credibility suggests that managers, by violating behavioral integrity, reduce their ability to induce change through their words. Several leadership theories outside the transformational leadership framework have also recognized the central importance of managerial word-action congruence for effective change management. Finally, discussions of organizational change and managerial fashions suggest profound challenges to word-action congruence. If these implications are accurate - if BI is in fact a necessary ingredient for effective transformational leadership, and if BI is so severely challenged in times of organizational change - then BI deserves notice as one of the pivotal challenges of successful change management.

Behavioral integrity is a fundamentally subjective construct that can be applied to referents at various levels of abstraction; from individual managers to organizations and perhaps even to the system at large''. As a relatively complex perception it is strongly influenced by social cognition processes, and some of these processes exacerbate nascent BI problems. Institutional pressures toward conformity to 
managerial fashions and organizational change efforts, individually and in series, appear to promote divergences between words and actions, and appear to have stimulated the emergence of behavioral integrity as a widespread problem.

The behavioral integrity framework highlights an apparently widespread problem with profound consequences. Further, this issue has not received systematic empirical attention. Instrumentation for reliable assessment of BI in field settings must be developed to empirically assess the relationships between BI and transformational leadership, trust, commitment, and receptiveness to change. Antecedent factors at organizational and individual levels should be articulated and tested. Laboratory settings allow assessment of the consequences of BI affirmations or violations independent of other personal characteristics and value content. Coordinated theory development, supported by systematic empirical research in both laboratory and field settings, will further elucidate this potentially critical construct.

Practitioners have, since the early days of organizational development writing, stressed the importance of executives walking their talk. The behavioral integrity perspective adds to this imperative a reminder of the importance of accurate selfrepresentation - in short, managers should consider the virtues of "talking their walk". 


\section{References}

Abrahamson, E. (1991), Managerial fads and fashions: the diffusion and rejection of innovations, Academy of Management Review, Vol. 16 No. 3, pp. 586-612.

Abrahamson, E. (1996), Management fashion, Academy of Management Review, Vol. 21 No. 1, pp. 254-85.

Argyris, C. (1970), Intervention Theory and Method: A Behavioral Science Review. Addison-Wesley Publishing, Reading, MA.

Argyris, C. (1990), Overcoming Organizational Defenses: Facilitating Organizational Learning, Allyn \& Bacon, Boston, MA.

Bartlett, C.A. and Ghoshal, S. (1995), Rebuilding behavioral context: turn process reengineering into people rejuvenation, Sloan Management Review, Fall, pp.11-23.

Bass, B.M. (1985), Leadership and Performance beyond Expectations, Free Press, New York, NY.

Bass, B.M. (1990), Bass and Stogdill's Handbook of Leadership: Theory, Research and Managerial Applications, 3rd ed., Free Press, New

York, NY.

Butler, J.K. Jr (1991), Toward understanding and measuring conditions of trust: evolution of a conditions of trust inventory, Journal of Management, Vol. 17 No. 3, pp. 643-63.

Bycio, P., Hackett, R.D. and Allen, J.S. (1995), Further assessments of Bass's (1985) conceptualization of transactional and transformational leadership, Journal of Applied Psychology, Vol. 80 No. 4, pp. 468-78.

Carlson, D.S. and Perrewe, P.L. (1995), Institutionalization of organizational ethics through transformational leadership, Journal of Business Ethics, Vol. 14 No. 10, pp. 829-38.

Carver, C.S. (1979), A cybernetic model of self-attention processes, Journal of Personality and Social Psychology, Vol. 37, pp. 125181.

Carver, C.S. and Scheier, M. F. (1981), The self-attention induced feedback loop and social facilitation, Journal of Experimental Social Psychology, Vol. 17, pp. 545-68.

Collins, J.C. and Porras, J.I. (1991), Organizational vision and visionary organizations, California Management Review, Vol. 34 No. 1, pp. 30-52.

Collins, J.C. and Porras, J.I. (1995), Building a visionary company , California Management Review, Vol. 37 No. 2, pp. 80-100. 
Collins, J.C. and Porras, J.I. (1996), Building your company s vision, Harvard Business Review (September-October), pp. 65-77.

Creed, W.E.D. and Miles, R.E. (1996), Trust in organizations: a conceptual framework linking organizational forms, managerial philosophies, and the opportunity costs of controls, in Kramer, R.M. and Tyler, T.R. (Eds), Trust in Organizations: Frontiers of Theory and Research, Sage Publications Inc., Thousand Oaks, CA, pp. $16-39$.

Cummings, L.L. and Bromiley, P. (1996), The organizational trust inventory (OTI): development and validation, in Kramer, R.M. and Tyler, T.R. (Eds), Trust in Organizations: Frontiers of Theory and Research, Sage Publications, Inc., Thousand Oaks, CA, pp. $302-30$.

Fiske, S.T. and Taylor, S.E. (1991), Social Cognition, 2nd ed., McGraw-Hill, New York, NY.

Gambetta, D.G. (1988), Can we trust trust?, in Gambetta, D.G. (Ed.), Trust: Making and Breaking Cooperative Relations, Basil Blackwell, oxford, pp. 213-38.

Ghoshal, S. and Bartlett, C.A. (1996), Rebuilding behavioral context: a blueprint for corporate renewal, Sloan Management Review, Winter, pp. 23-36.

Hamel, G. and Prahalad, C.K. (1989), Strategic intent, Harvard Business Review, May-June, pp. 63-76.

Hamel, G. and Prahalad, C.K. (1994), Competing for the Future, Harvard Business School Press, Boston, MA.

Hinkin, T.R. and Tracey, J.B. (1999), The relevance of charisma for transformational leadership in stable organizations, Journal of organizational Change Management, Vol. 12 No. 2, pp. 105-19.

Hosmer, L.T. (1995), Trust: the connecting link between organizational theory and philosophic ethics, Academy of Management Review, Vol. 20 No. 2, pp. 379-403.

Korsgaard, M.A., Schweiger, D.M. and Sapienza, H.J. (1995), Building commitment, attachment, and trust in strategic decision-making teams: the role of procedural justice, Academy of Management Journal, Vol. 38 No. 1, pp. 60-84.

Kouzes, J.M. and Posner, B.Z. (1992), Ethical leaders: an essay about being in love, Journal of Business Ethics, Vol. 11 No. 5, pp. 479-84.

Kouzes, J.M. and Posner, B.Z. (1993), Credibility: How Leaders Gain and Lose it, Why People Demand it, Jossey-Bass, San Francisco, CA. 
Kramer, R.M. (1996), Divergent realities and convergent disappointments in the hierarchic relation: trust and the intuitive auditor at work, in Kramer, R.M. and Tyler, T.R. (Eds), Trust in Organizations: Frontiers of Theory and Research, Sage Publications, Inc., Thousand Oaks, CA, pp. 216-44.

Lewicki, R.J. and Bunker, B.B. (1996), Developing and maintaining trust in work relationships, in Kramer, R. and Tyler,T. (Eds), Trust in Organizations: Frontiers of Theory and Research, Sage Publications, Inc., Thousand Oaks, CA, pp. 114-39.

McAllister, D.J. (1995), Affect- and cognition-based trust as foundations for interpersonal cooperation in organizations, Academy of Management Journal, Vol. 38, pp. 24-59.

McGregor, D. (1967), The Professional Manager, McGraw-Hill, New York, NY.

Mayer, R.C., Davis, J.H. and Schoorman, F.D. (1995), An integrative model of organizational trust, Academy of Management Review, Vol. 20 No. 3, pp. 709-34.

Mishra, A.K. (1996), Organizational responses to crisis: the centrality of trust, in Kramer, R. and Tyler, T. (Eds), Trust in Organizations: Frontiers of Theory and Research, Sage Publications, Inc., Thousand Oaks, CA, pp. 261-87.

Random House (1975), Random House College Dictionary, revised ed., Random House, New York, NY.

Robinson, S.L. (1996), Trust and breach of the psychological contract , Administrative Science Quarterly, Vol. 41, pp. 574-99.

Rotter, J.B. (1967), A new scale for the measurement of interpersonal trust, Journal of Personality, Vol. 35, pp. 651-65.

Shapiro, E.C. (1995), Fad Surfing in the Boardroom: Reclaiming the Courage to Manage in the Age of Instant Answers, Addison-Wesley Publishing, New York, NY.

Simons, T. (1997), Empty words and whiffs of hypocrisy: behavioral integrity - the fit between words and deeds as a research focus, unpublished manuscript.

Swann, W.B. and Read, S.J. (1981), Acquiring self-knowledge: the search for feedback that fits, Journal of Personality and Social Psychology, Vol. 41, pp. 1119-28.

Terry, R.W. (1993), Authentic Leadership: Courage in Action, JosseyBass, San Francisco, CA.

Tyler, T.R. and Degoey, P. (1996), Trust in organizational authorities: the influence of motive attributions on willingness 
to accept decisions, in Kramer, R.M. and Tyler, T.R. (Eds), Trust in Organizations: Frontiers of Theory and Research, Sage Publications, Inc., Thousand Oaks, CA, pp. 331-56.

Yukl, G. (1989), Managerial leadership: a review of theory and, Journal of Management, Vol. 15 No. 2, pp. 251-89.

Zucker, L.G. (1986), Production of trust: institutional sources of economic structure, 1840-1920, in Cummings, L.L. and Staw, B. (Eds), Research in Organizational Behavior, JAI Press, Greenwich, CT, Vol. 8, pp. 53-111. 